\title{
Comparing the Sensitivity of Visual Evoked Potential and Standard Achromatic Perimetry in Diagnosis of Optic Neuritis
}

\author{
Kourosh Shahraki ${ }^{1,2}$, Mostafa Soltan Sanjari ${ }^{2 *}$, Kaveh Abri Aghdam ${ }^{2}$, Hamidreza Rokhsat Yazdi ${ }^{2}$, Kianoush \\ Shahraki ${ }^{3}$ and Vida Ilkhani Pak ${ }^{2}$
}

${ }^{1}$ Department of Ophthalmology, Zahedan University of Medical Sciences, Iran

${ }^{2}$ Department of Ophthalmology, Iran University of Medical Sciences, Iran

${ }^{3}$ Department of Ophthalmology, Tehran University of Medical Sciences, Iran

Submission: March 02, 2017; Published: April 27, 2017

*Corresponding author: Mostafa Soltan Sanjari, Department of Ophthalmology, Rasoul Akram Hospital, Iran University of Medical Sciences, Tehran, Iran, Tel: +989155401185; Email:kourosh.shahyar@gmail.com

\begin{abstract}
Purpose: To evaluate the diagnostic power of Visual Evoked Potential (VEP) and Standard Achromatic Perimetry (SAP) in a group of patients with Multiple Sclerosis (MS) and a history of optic neuritis (ON).

Methods: 136 eyes of 68 patients ( 11 male and 57 female, average age 27.18 years) with a confirmed diagnosis of MS underwent SAP and pattern VEPs. 67 eyes (49.2\%) had no history of ocular involvement and a negative ophthalmologic examination, while 69 had proven ON according to physical examination. The mean deviation (MD) and the pattern standard deviation (PSD) of perimetry and the amplitude \& latency of VEP in both normal and abnormal eyes were recorded. MD \& PSD $<0.5 \%$ and pl00 latency more than 118 millisecond were considered abnormal.
\end{abstract}

Results: MD was abnormal in $93.9 \%$ of the eyes with ON, PSD was abnormal in $69.4 \%$ and latency was abnormal in $55 \%$ of the affected eyes with ON. In overall, VEP can diagnose $55 \%$ of the eyes affected with ON and SAP can diagnose $96 \%$. In statistical analysis of MD, PSD, latency and amplitude values with Mann-Whitney Test MD and PSD were statistically significant (MD has p $<0.001$, PSD has P $<0.05$, latency has $\mathrm{p}=0.83$ and amplitude has $\mathrm{p}=0.38$ ).

Conclusion: The results of this study demonstrate that SAP is more sensitive than VEP in the diagnosis of ON. SAP is a less operator and patient dependent technique and the patient test reliability can be assessed with parameters such as False-positive response rate, Falsenegative response rate, Fixation loss \& Short-term fluctuation measurement. Because of these advantages, SAP has better sensitivity than VEP in the diagnosis of ON. Our results suggest that clinical and subclinical visual involvement of ON can be better diagnosed using both SAP and VEP tests, together.

Keywords: Diagnostic power of SAP \& VEP; Multiple sclerosis

\section{Introduction}

Multiple sclerosis (MS) is an autoimmune disease that involves the Optic Nerve, brain and spinal cord by damaging the myelin sheath [1]. The disease can affect patients' visual pathway and therefore lead to Optic Neuritis (ON) which is an eye discomfort accompanied by decreased visual acuity, changes in the visual field, uncontrollable rapid eye movements and double vision (clinical and frequent subclinical evident manifestations) [1-3]. De-myelinating disease leads to less responses of the brain and the optic nerve which is detected by the visual evoked potential [3-5]. Alterations in the visual evoked potential (VEP) and standard achromatic perimetry (SAP) have been reported to be useful in patients with MS. Many studies have shown the presence of abnormality in the results of VEP and SAP in optic neuritis [6], but there is little agreement about the prevalence of these abnormalities or about which examination is more sensitive [7-10]. In this article, our aim is to evaluate the diagnostic power of SAP \& VEP in a group of patients with Multiple Sclerosis (MS) and a history of optic neuritis. 


\section{Material and Methods}

Sixty eight patients with ON and MS were recruited from the neurology and neuro-ophthalmology clinics of Rassoul Akram hospital in 2010-2011. The diagnosis of ON/MS was made based on standard clinical symptoms, examination findings, and radiologic abnormalities. In all patients, the disease was in remission and no patient was affected by any general disease apart from MS [11].

The diagnosis of ON was based on clinical signs and symptoms; such as: history of a progressive decrease of vision, color vision deficit, painful eye movements, fundus examination and relative afferent pupillary defect (RAPD) which is diagnosed by a neurologist or neuro-ophthalmologist. Patients voluntarily participated in this study and all participants were enrolled after an informed consent was obtained. All patients underwent full ophthalmic examination, including best-corrected visual acuity (BCVA) measurement, slit lamp biomicroscopy, applantation tonometry, and fundus examination after pupillary dilation. VEP pattern reversal was performed (Sirius Galileo; Esaote Biomedica, Florence, Italy). Latency and amplitude were recorded and AP100 latency $>118 m$ s (i.e., 2SD above the mean) was considered abnormal.
Standard achromatic perimetry (SAP) was performed by means of the Humphrey Field Analyzer 750 (model 750; Carl Zeiss Meditec, Dublin, CA) using the 30-2 program with the Swedish interactive threshold algorithm (SITA) standard strategy. Two consecutive visual field examinations were performed for each patient, but only the second was evaluated for the purpose of the study and only if reliability indices were normal. The criteria for abnormality were mean deviation (MD) or pattern standard deviation (PSD) and were labeled abnormal by the instrument's software. VEP and SAP were done for all patients with one expert optometrist.

Patient data were collected through questionnaires, respectively, were entered into the SPSS software version 18.0 and were then analyzed. Maximum, minimum, and $\mathrm{SD} \pm$ Mean were reported for the quantitative data and for the qualitative data, the number (percentage) was stated. The Chi-Square test, with the aid of SPPS software was used to evaluate the relationship between qualitative variables and Mann-Whitney test was used for evaluation of normality between data and a $P$-value of $<0.05$ was considered valuable. VEP and SAP were done in all 68 patients (136 eyes). The age, sex, MD, PSD, amplitude and latency recorded are shown in Table 1.

Table 1: The mean of age, MD, PSD, amplitude and latency, according to patients' sex.

\begin{tabular}{|c|c|c|c|c|c|}
\hline SEX & Age & PSD & MD & Amplitude & Latency \\
\hline Female & $26.88 \pm 8.1$ & $4.65 \pm 3.7$ & $-7.67 \pm 8.4$ & $9.12 \pm 6.7$ & $111.94 \pm 19.5$ \\
\hline Male & $28.73 \pm 10.5$ & $5.73 \pm 3.1$ & $-8.84 \pm 8.2$ & $7.15 \pm 4.5$ & $112.48 \pm 16.42$ \\
\hline Total & $27.18 \pm 8.5$ & $4.82 \pm 3.6$ & $-7.85 \pm 8.3$ & $8.79 \pm 6.4$ & 0.2 \\
\hline p-value & 0.5 & 0.2 & 0.6 & 0.9 \\
\hline
\end{tabular}

\section{Results}

From the 68 patients that were included in this study, 11 were male $(16.2 \%)$ and 57 were female $(83.8 \%)$. The mean \pm SD age of the patients was $27.18 \pm 8.5$ (range:14-61 years old). $49.6 \%$ of the eyes that were included in the study were normal and $50.4 \%$ had ON. The mean MD value was $-7.86 \mathrm{db}$ (with SD: 8.4) with a range of $-34.49 \mathrm{db}$ to $7.57 \mathrm{db}$. Also, the mean \pm SD MD value in normal eyes was $-4.89 \mathrm{db} \pm 7.12$ with a range of $-34.49 \mathrm{db}$ and $7.57 \mathrm{db}$, while the mean value \pm SD of MD in the affected eyes was $-10.63 \mathrm{db} \pm 8.98$ with a minimum of $-31.28 \mathrm{db}$ and a $5.18 \mathrm{db}$ maximum. MD was negative in $19.1 \%$ of the normal eyes and positive in $80.9 \%$, while being negative in $6.1 \%$ and positive in $93.9 \%$ of the eyes affected with $\mathrm{ON}$. The mean \pm SD, PSD value was $4.82 \mathrm{~d} 3.6$ with a minimum of $1.06 \mathrm{db}$ and a maximum of $14.46 \mathrm{db}$. PSD value in normal eyes had a mean \pm SD of $3.55 \mathrm{db} \pm 3.09$ with a minimum and maximum of $1.06 \mathrm{db}$ and $14.13 \mathrm{db}$; and the mean value of PSD in affected eyes was $5.78 \mathrm{db}(\mathrm{SD}: \pm 3.75)$ with a minimum of $1.34 \mathrm{db}$ and a $14.13 \mathrm{db}$ maximum. PSD was negative in $59.6 \%$ and positive in $40.4 \%$ of the normal eyes and $30.6 \%$ negative and $69.4 \%$ positive in the affected eyes with ON.

The mean \pm SD latency value was $112.03 \mathrm{~ms} \pm 18.98$ with a range of $58 \mathrm{~ms}$ to $157 \mathrm{~ms}$. The mean \pm SD latency value in normal eyes was $109.98 \mathrm{~ms} \pm 17.03$ with a range of $58 \mathrm{~ms}$ to $157 \mathrm{~ms}$ while in the affected eyes, the mean \pm SD value of latency was $114.07 \mathrm{~ms} \pm 19.85$ with a $58 \mathrm{~ms}$ minimum and a maximum of $150 \mathrm{~ms}$. Also, latency was negative in $70.6 \%$ and positive in $29.4 \%$ of the normal eyes, while being $45 \%$ negative and $55 \%$ positive in the affected eyes with $\mathrm{ON}$.

The mean \pm SD amplitude value was $8.79 \mu v \pm 6.41$ with the minimum of $0.5 \mu \mathrm{v}$ and a maximum of $34.9 \mu \mathrm{v}$. The mean \pm SD amplitude value in normal eyes was $10.04 \mu \mathrm{v} \pm 6.76$ with a range of $1.13 \mu \mathrm{v}$ to $27.90 \mu \mathrm{v}$ and in the affected eyes, the mean \pm SD value of amplitude was $7.71 \mu \mathrm{v} \pm 5.86$ with a $0.50 \mu \mathrm{v}$ minimum and a maximum of $27.90 \mu \mathrm{v}$. 
In statistical analysis of MD, PSD, latency and amplitude values with Mann-Whitney Test, MD has $\mathrm{p}<0.001$, PSD has
$\mathrm{P}<0.05$, that statistically significant but latency has $\mathrm{p}=0.83$ and amplitude has $\mathrm{p}=0.38$ (Table2).

Table 2: Outcome of Perimeter, MD and PSD technique according to patient diagnosis.

\begin{tabular}{|c|c|c|c|c|}
\hline C & Test Outcome & Total & p-value & \\
\hline Perimeter & Negative & Positive & 0.011 \\
\hline Normal & $10(10.2 \%)$ & $38(38.8 \%)$ & $48(49.0 \%)$ & $50(51.0 \%)$ \\
\hline Abnormal & $2(2.0 \%)$ & $48(49.0 \%)$ & $98(100.0 \%)$ & \\
\hline Total & $12(12.2 \%)$ & $86(87.8 \%)$ & $47(49.0 \%)$ & 0.051 \\
\hline Normal & $9(9.4 \%)$ & $38(36.9 \%)$ & $49(51.0 \%)$ & \\
\hline Abnormal & $3(3.1 \%)$ & $46(47.9 \%)$ & $96(100.0 \%)$ & \\
\hline Total & $12(12.5 \%)$ & $84(87.5 \%)$ & & \\
\hline Normal & $28(29.2 \%)$ & $19(19.8 \%)$ & $47(49.0 \%)$ & \\
\hline Abnormal & $15(15.6 \%)$ & $34(35.4 \%)$ & $49(51.0 \%)$ & \\
\hline Total & $43(44.8 \%)$ & $53(55.2 \%)$ & $96(100.0 \%)$ & \\
\hline
\end{tabular}

\section{Discussion}

In many studies, subclinical alterations can be helpful in diagnosing some cases of the visual system in both normal and Multiple Sclerosis patients, but we found that there was little agreement about the prevalence of these abnormalities [12-15] and the fact that which abnormality has the most sensitivity $(6,14)$. In our study there was no single examination detected in all cases of visual involvement. So, the VEP P100 latency is the most diffuse and also the parameter of it had been used for detection the optic nerve involvement, but it is not very sensitive for the diagnosis of post chiasmal localizations. The results of our study had been impacted by other related studies too.

On other hand, the result of other studies shows that the VEP P100 latency cannot detect all cases of optic nerve involvement [10]. Also, some studies demonstrate that automated perimetery can too be an excellent tool in evaluating neuro-ophthalmologic disorders. Our studies show that SAP is more sensitive than VEP in the diagnosis of ON. In overall, VEP can diagnose $55 \%$ of the affected eyes with ON and SAP can diagnose $96 \%$. In statistical analysis of MD, PSD, latency and amplitude values with MannWhitney Test, MD has $\mathrm{p}<0.001$ and PSD has $\mathrm{P}<0.05$ and latency has $\mathrm{p}=0.83$ and amplitude has $\mathrm{p}=0.38$. SAP and is a less operator and patient-dependent technique and the patient test reliability can be assessed with parameters such as False-positive response rate, False-negative response rate, Fixation loss \& Short-term fluctuation measurement.

In an article by Ruseckaite $\mathrm{R}$ et al. [16], the results on Frequency doubling illusion VEPs and automated perimetry in Multiple Sclerosis is shown. The recordings in the study were obtained from 27 Normal subjects, 26MS patients who had experienced Optic Neuritis (MSON) and 24MS patients without a history of ON (MSNON). Ruseckaite R et al. [16] study also demonstrated that discriminant models based on the Frequency Doubling Technology (FDT) thresholds and multi focal VEP (mfVEPs) were able to diagnose more that $90 \%$ of MSON patients, but performed poorly for MSNON patients.

Because of these advantages, SAP can have better sensitivity than VEP in the diagnosis of ON. (96\%vs55\%). Other advantages of SAP are as follows:

a. Standardized testing conditions, which allow better serial and inter- institutional comparisons of fields

b. Less technician dependence which improves sensitivity.

c. Producing numerical data that are amenable to statistical analysis for comparisons and clinical studies.

In VEP, if a patient loses focus on the target, the test results may be false negative or false positive. For Most clinical situations, the VEP is of limited use. It is subject to numerous factors that may produce abnormal waveforms in the absence of visual pathway damage, including uncorrected refractive error, media opacity, amblyopia, fatigue, and inattention (either intentional or unintentional). In Most cases, the VEP is unnecessary for the diagnosis of optic neuropathy and is less accurate to quantify it than perimetry $[8,9]$

The two scenarios in which VEPs remain clinically useful are: First, the evaluation of the integrity of the visual pathway in infants or inarticulate adults. In this case, a preserved flash or pattern response confirms intact pathways and an abnormal flash response consistently reflects gross impairment. An abnormal pattern response is less useful, as it may indicate damage or this may be a false- negative result. Second, confirming intact visual pathways in patients with markedly abnormal subjective visual responses of a suspected nonorganic origin $[10,11]$. 
Corallo G et al. [17], in a study about conventional perimetry and visual evoked potentials in the assessment of patients with Multiple Sclerosis, demonstrated that the group of asymptomatic subjects had abnormal Conventional Automated Perimetry (CAP) in 1 eye (6.25\%), abnormal Short-wavelength automated perimetry (SWAP) in 9 (56.2\%), abnormal FDT in 11 (68.7\%), and abnormal VEPs in 7 (43.7\%). Also, Corallo G et al. [17] show that the combined use of all techniques allowed the researchers to identify silent optic nerve impairment in 15 (93.7\%) eyes of MS patients. In another study by Della et al. [18], on the nerve fiber layer analysis with GDx with a variable corneal compensator in patients with Multiple Sclerosis, the result is shown that GDx VCC is less able to detect early defects in MS patients compared to the currently used standard techniques of SAP and VEPs.

At last in our cases, intact pattern had been developed a measure of expected acuity when stimuli of various sizes and confirms an intact visual pathway. Because voluntary inattention or de focusing may markedly reduce the pattern waveform, again, an abnormal or absent pattern response does not confirm organic disease.

\section{Conclusion}

According to the results of this study and what was discussed above, we suggest using both VEP and SAP tests for the diagnosis and follow up of Optic Neuritis in patients with Multiple Sclerosis.

\section{Declaration}

a) The manuscript is original work of author. All data, tables, figures, etc. used in the manuscript are prepared originally by authors, otherwise the sources are cited and reprint permission is attached.

b) The manuscript has not been and will not be published elsewhere or submitted elsewhere for publication.

c) Authors mention that there is no conflict of interest in this study.

\section{References}

1. Calabresi P (2007) Multiple sclerosis and demylinating conditions of the central nervous system. In: Goldman L, Ausicllo D (Eds.), cecil medicine. (23 ${ }^{\text {rd }}$ edn), pa:saunders Elsevier, Philadelphia, USA, p. 436.

2. K Shirzadi, Amirdehi AR, Makateb A, Shahraki K, Khosravifard K (2015) Studying the Effect of Tropicamide Various Concentrations on Routine Dilation of the Pupil. Biomedical and Pharmacology Journal 8(2): 885-889.

3. Beck RW, Clearu PA, Anderson MM, Keltner JL, Shults WT, et al. (1992) A Randomized controlled trial of corticosteroid in the treatment of acute optic neuritis. The Optic Neuritis Study Group. N Eng J Med 326(9): 581-588.
4. Dario Sisto, Maria Trojano, Michele Vetrugno, Tiziana Trabucco, Giovanni Iliceto, et al. (2005) Subclinical Visual Involvement in Multiple Sclerosis: A Study by MRI, VEPs, Frequency-Doubling Perimetry, Standard Perimetry, and Contrast Sensitivity. IOVS 46(4): 1264-1268.

5. Sanders EA, Reulen JP, Hongenhuis LA, Vander EA (1985) Electrophysiological disorder in MS and Optic neuritis. Can J Neural Sci 12(4): 308-313.

6. Fraser CL, Klistorrer A, Graham SL, Garrick R, Billson FA, et al. (2006) Multifocal visual evoked potential analysis of inflamatoy or demyelinatory optic neuritis. Ophthalmology 113(2): 323.

7. Wall M, Neahring RK, Woodward KR (2002) Sensitivity and specificity of frequency doubling perimetry in neuro-ophthalmic disorders: a comparison with conventional automated perimetry. Invest Ophthalmol Vis Sci 43(4): 1277-1283.

8. Abdolhoseinpour H, Mehrabi F, Shahraki K, Khoshnood RJ, Masoumi B, et al. (2016) Investigation of serum levels and tissue expression of two genes IGFBP-2 and IGFBP-3 act as potential biomarker for predicting the progression and survival in patients with glioblastoma multiforme. J Neurol Sci 366: 202-206.

9. Shirzadi K, Shahraki K, Yahaghi E, Makateb A, Khosravifard K (2016) Comparison of Manual Refraction Versus Autorefraction in 60 Diabetic Retinopathy Patients. Med Arch 70(4): 280-283.

10. Evangelou N, Konz D, Esiri MM, Smith S, Palace J, et al. (2001) Sizeselective neuronal changes in the anterior optic pathway suggest a differential susceptibility to injury in multiple sclerosis. Brain $124(\mathrm{Pt}$ 9):1813-1820.

11. Fujito N, Adachi-UE (2000) Frequency doubling perimetry in resolved optic neuritis. Invest Ophthall Vis Sci 41(9): 2558-2560.

12. Kjaer M (1983) Evoked potentials: with special reference to the diagnostic value in multiple sclerosis. Acta Neurol Scan 67(2): 67-89.

13. Lashkari MH, Shahraki K, Najafi, et al. (2014) Evaluation of the optic nerve head and peripapillary retinal nerve fiber layer changes in warplanes pilots. Int J Curr Res Aca Rev 2(8): 217-221.

14. Nezami A, Khoshvaghti A, Najafi A, Koroush S, Saber M, et al. (2014) Evaluation of the intraocular pressure changes after flight with warplanes. Int J Curr Res Aca Rev 2(8): 222-225.

15. Saraux H, Nordmann JP (1990) Value of a study of contrast sensitivity in the evaluation of visual function: application to pathology and visual selection. Bull Acad Natl Med 174(4): 497-506.

16. Ruseckaite R, Maddess T, Danta G, James AC (2006) Frequency doubling illusion VEPs and automated perimetry in multiple sclerosis. Doc Ophthalmol 113(1): 29-41.

17. Corallo G, Cicinelli S, Papadia M, Bandini F, Uccelli A, et al. (2005) Conventional perimetry, short-wavelength automated perimetry, frequency-doubling technology, and visual evoked potentials in the assessment of patients with multiple sclerosis. Eur J Ophthalmol 15(6): 730-738.

18. Della MG, Bacchetti S, Zeppieri M, Brusini P, Cutuli D, et al. (2007) Nerve fibre layer analysis with GDx with a variable corneal compensator in patients with multiple sclerosis. Ophthalmologica 221(3): 186-189. 
This work is licensed under Creative Commons Attribution 4.0 Licens DOI: $10.19080 /$ JOJO.2017.02.555600
Your next submission with Juniper Publishers will reach you the below assets

- Quality Editorial service

- Swift Peer Review

- Reprints availability

- E-prints Service

- Manuscript Podcast for convenient understanding

- Global attainment for your research

- Manuscript accessibility in different formats ( Pdf, E-pub, Full Text, Audio)

- Unceasing customer service

Track the below URL for one-step submission https://juniperpublishers.com/online-submission.php 